\title{
STRATEGI KOMUNIKASI PEMBELAJARAN BAHASA INGGRIS UNTUK MENINGKATKAN KEMAMPUAN BERBAHASA DI SMPIT NURUL ISLAH BANDA ACEH
}

\author{
Rina Syafitri \\ FakultasPertanian \\ Universitas Teuku Umar \\ email: rinasyafitri@utu.ac.id
}

\begin{abstract}
Education is a very important element to create quality human resources.Learning is done every day of the week starting from morningtill night for six months more quickly proven to help their improve their languageskills. By using the communication strategy learning in teaching and learning in the SMPIT Nurul Ishlah. The purpose of this study was to determine the learningstrategies used in the the SMPIT Nurul Ishlah Banda Aceh, teacher communication process with thestudents in learning English, and know the communication media used in teachingand learning in the SMPIT Nurul Ishlah Banda Aceh.This study uses qualitative research methods with the presentation of analysisdesktriptif. The informants are teachers as lecturers and students of Englishvillages were selected purposively. Data collection techniques used wereobservation, interviews, and documentation. The validity of the technique used inthis research is triangulation and extension of participation. In analyzing the data, the researcher used the Constant Comparative Method.The results of the research is shown that students in the SMPIT Nurul Ishlah at learning procesess applied communication strategies by doing class instruction, word coinage, codeswitching, and appeal for help, without the knowing. That was happed autonomous.
\end{abstract}

Keywords : Communication Strategy,English, SMPIT Nurul Ishlah, Teaching

\section{PENDAHULUAN}

Pendidikan merupakan elemen yang sangat penting untuk menciptakan sumber daya yangberkualitas, cerdas, damai, terbuka,demokratis dan mampu bersaing sertadapat meningkatkan kesejahteraansemua warga negara Indonesia.Di dalam prosespembelajaran, atau lebih luasnyaproses pendidikan, terkandung unsurunsur yang mendukungnya. Unsur-unsur tersebut antara lain adalah orang yang belajar, pihak yang membantu menyebabkan belajar, danfaktor-faktor lain yang memengaruhi kedua pihak tersebut dalam melaksanakan fungsi masing-masing, termasuk didalamnya unsur komunikasi. Pembelajaran merupakan suatu proses komunikasi. Komunikasi adalah proses pengiriman informasi dari satu pihak kepada pihak lain untuk tujuan tertentu. Komunikasi dikatakan efektif apabila komunikasi yang terjadi menimbulkan arus informasi dua arah, yaitu dengan munculnyafeedback dari pihak penerima pesan.Seiring perkembangan zaman dan kemajuan teknologi, kemampuan menguasai bahasa asing, seperti bahasa inggris sangat diperlukan.

Dalam komunikasi lisan, ada banyak faktor menghambat kompetensi komunikatif seseorang, seperti masalah linguistik mencakup masalah gramatikal, leksikal dan fonologi(Gan, 2013). Masalah tata bahasa berkaitan dengan pembentukan kalimat yang benar, sementara masalah leksikal melibatkan keterbatasan kosa kata. Kemudian,masalah fonologis mengacu pada cara untuk mengucapkan kata, peserta didik harus menggunakan beberapa strategi untuk 
tetap memegang komunikasi. Strategi yang digunakan dalam komunikasi diidentifikasi sebagai strategi komunikasi (communication strategies). Strategi komunikasi didefinisikan sebagai sarana pemecahan masalah dalam komunikasi yang digunakan oleh bahasa kedua atau pelajar bahasa asing dalam hal mencapai tujuan komunikatif tertentu (Faerch dan Kaspper, 1983). Dalam kemampuan berbahasa Inggris Lingkungan sangat berperan dominan mendukung tercapainya kemampuan berbahasa dengan baik dan benar serta berterima. Dalam hal inilingkungan dibagi menjadi dua, yaitu Terdapat dua faktor lingkungan, yaitu makro dan mikro. Faktor lingkungan makro meliputi (1) kealamiahan bahasa yang didengar; (2) peranan si pembelajar dalam komunikasi; (3) ketersediaan rujukan konkret untuk menjelaskan makna; dan (4) siapa model bahasa sasaran sedangkan faktor lingkungan mikro mencakup (1) kemenonjolan salience), yaitu mudahnya suatu struktur untuk dilihat atau didengar; (2) umpan balik, yaitu tanggapanpendengar atau pembaca terhadap tuturan atau tulisan si pembelajar; dan (3)frekuensi, yaitu seringnya si pembelajar mendengar atau melihat struktur tertentu(Dulay, Burt, dan Krashen, 1982).

Penelitian ini bertujuan untuk(1) Mengetahui strategi pembelajaranbahasa inggris apa yang diterapkan di Sekolah Menengah Pertama Islam Terpadu (SMPIT) Nurul Ishlah Banda Aceh. (2)Mengetahui proses komunikasi siswa/siswi dan guru dalampembelajaran bahasa Inggris yangdilakukan di Sekolah Menengah Pertama Islam Terpadu (SMPIT) Nurul Ishlah Banda Aceh (3) Mengetahui penggunaanmedia komunikasi yang digunakandalam pembelajaran bahasa Inggris di Sekolah Menengah Pertama Islam Terpadu (SMPIT) Nurul Ishlah Banda Aceh.

Berdasarkanlatar belakang di atas, penelitiberkeinginan untuk mengetahui strategi komunikasi yang digunakanoleh siswa/siswi Sekolah Menengah Pertama Islam Terpadu (SMPIT) Nurul Ishlah Banda Aceh. Penelitimenganggap bahwa sebagai pembelajarbahasa asing mereka mungkin memilikibeberapa keterbatasan pengetahuanmereka tentang tata bahasa dan strukturaturan naming dengan metode dan saranadan prasarana yang mendukung maka mereka mampu menggunakan bahasaInggris dengan lancar dan penuh percayadiri.

\section{KAJIAN PUSTAKA \\ Komunikasi}

Banyaknya disiplin ilmu yang telah memberi masukan terhadapperkembangan ilmu komunikasi, misalnya psikologi, sosiologi, antropologi, ilmupolitik, ilmu manajemen, linguistik, dan sebagainya, menyebabkan banyaknyadefinisi tentang komunikasi yang telah dibuat oleh para pakar menurut bidang ilmunya. Hovland dalam Mulyana,2007) mendefinisikan komunikasiadalah proses yang memungkinkan seseorang (komunikator)menyampaikanrangsangan (biasanya lambang-lambang verbal) untuk mengubah prilaku oranglain (komunikate).

\section{Komunikasi efektif}

Semua orang tentu saja mengharapkan komunikasi yang dilakukannyaefektif. Komunikasi yang efektif menurut Tubbs dan Mosspaling tidak menimbulkan lima hal yaitu:

1. Pengertian, pengertian artinya penerimaan yang cermat dari isi stimuli seperti yang dimaksudkan oleh komunikator.

2. Kesenangan, komunikasi dimaksudkan untuk menjadikan hubungan kita hangat, akrab dan menyenangkan.

3. Pengaruh pada sikap, komunikasi dilakukan agar komunikan bertindak sesuai harapan komunikator berdasarkan atas kehendaknya sendiri.

4. Hubungan yang semakin baik, dengan berkomunikasi maka akan tercipta hubungan yang positif dan mempertahankan hubungan yang saling memuaskan. 
5. Tindakan, menimbulkan tindakan adalah indikator efektivitas dari komunikasi.

Tindakan adalah hasil akumilasi dari seluruh proses komunikasi. (Rahkmat, 2007).

Komunikasi disebut efektif apabila penerima menginterpestasikan pesanyang diterimanya sebagaimana yang dimaksudkan oleh pengirim.Kenyataannya,sering kita gagal salingmemahami. Sumber utama kesalahfahaman dalamkomunikasi adalah cara penerima menangkap makna suatu pesan berbeda yangdimaksud oleh pengirim, karena pengirim gagal mengkomunikasi maksudnyadengan tepat (Supratiknya, 2009).

\section{Strategi Komunikasi}

Strategi komunikasi yangdiusulkan oleh Bialystok (1990) adalahkemudahan dan kelancaran akrab denganyang kami jual dari satu ide ke yangberikutnya dalam bahasa pertama kamiterus hancur oleh beberapa kesenjangandalam pengetahuan kita tentang bahasa kedua. Dia juga mengacu pada strategikomunikasi sebagai teknik yang digunakankarena kurangnya pengetahuan L2 yangdia sebut "celah " dan peserta didikberusaha untuk memasok kesenjanganyang strategi komunikasi. Di sisi lain, Ellis (1997) mendefinisikan strategi komunikasisebagai cara untuk menjaga percakapanterjadi sebagai pelajar menemukanmasalahdalam menyampaikan maknayang dimaksudkan karena pengetahuan memadai mereka. Namun, Thornbury(2008) menyatakan ciri strategi komunikasisebagai kerjasama dua lawan bicara untukberurusan dengan makna dalam situasi dimana struktur makna yang diperlukan mungkin tidak muncul.

Faerch dan Kasper (1983)mendefinisikan strategi komunikasi sebagai "rencana berpotensi sadar untukmemecahkan apa yang harus hadirseorang individu itu sendiri sebagaimasalah dalam mencapai tujuan komunikatif tertentu. Namun, merekamengusulkan dua jenis utama dari strategikomunikasi: strategi pengurangan diaturoleh perilaku menghindar, dan strategipencapaian diatur oleh perilaku prestasi. Hubungan antara masalah, jenisperilaku dan jenis strategi diwakili dalamGambar 1di bawah ini:

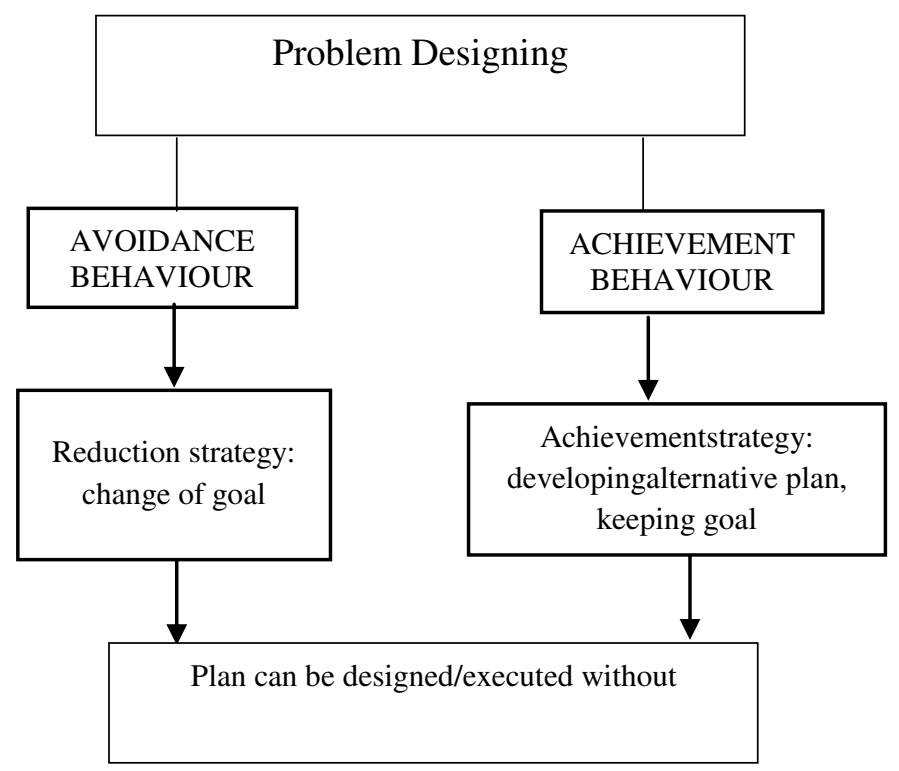

Gambar 1. Dua Tipe Utama Strategi Komunikasi

Sumber : (Faerch and Kasper, 1983).

Hal ini dapat disimpulkan dariGambar diatas masalah komunikasi yangdihadapi oleh peserta didik menyebabkanperilaku menghindar atau perilaku prestasi.Ketika peserta didik 
mengubah tujuanmereka komunikasi, itu berarti bahwamereka menggunakan strategipengurangan dan ketika mereka terusberusaha untuk mengembangkan rencanadan tujuan alternatif, mereka dianggapmempekerjakan strategi pencapaian.Sebagai hasil dari kedua strategi,komunikasi yang terencana dapatdijalankan tanpa masalah. Brown (2007) menyatakan bahwacara terbaik untuk memahami makna daristrategi komunikasi adalah tapi belajar daftarkhas strategi tersebut dari taksonomistrategi komunikasi diadaptasi dari donyei(1995) yang dikategorikan seperti pada Gambar 2 di bawah ini.

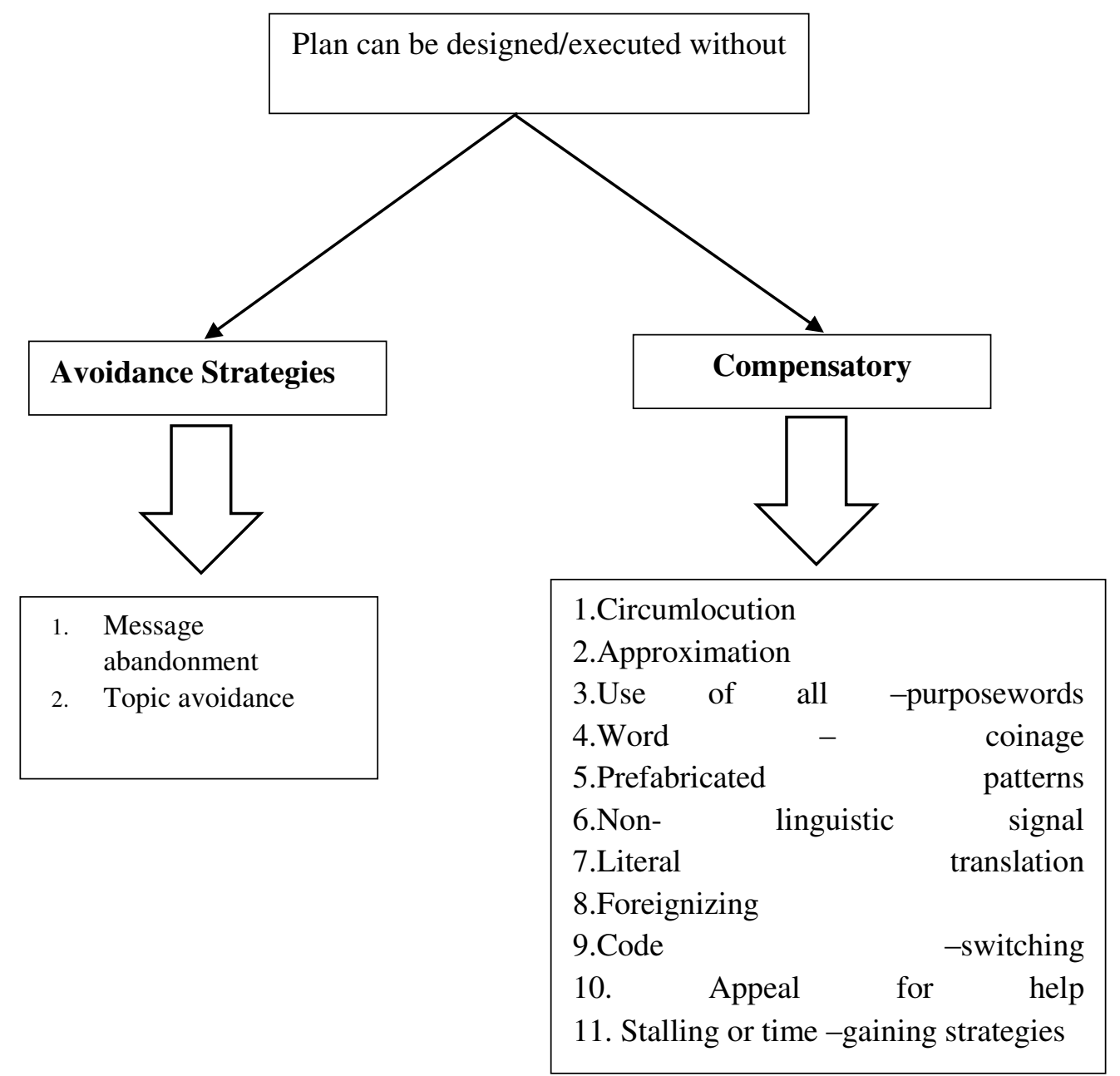

Gambar 2. Taksonomi strategis komunikasi yang diadaptasi dari Donyei (1995)

Strategi Komunikasiberhasil atau tidaknyakegiatan komunikasi secara efektifbanyak ditentukan oleh strategikomunikasi, strategi pada hakikatnyaadalah perencanaan (planning) danmanajemen (management) untukmencapai suatu tujuan. Akan tetapi,untuk mencapai tujuan tersebut,strategi tidak berfungsi sebagai petajalan yang menunjukkan arah saja,melainkan harus mampu menunjukanbagaimana taktikoperasionalnya. Menurut Salusu ada empat Tingkatantingkatan strategi. Keseluruhannyadisebut master strategy yaitu (a)Enterprise Strategy, Strategi iniberkaitan dengan respon masyarakat.Setiap organisasi mempunyaihubungan dengan masyarakat.Masyarakat adalah kelompok yangberada diluar 
organisasi yang tidakdapat dikontrol. (b) Corporate Strategy, Strategi ini berkaitan dengan misiorganisasi sehingga sering disebutGrand Strategy yang meliputi bidangyang digeluti oleh suatu organisasi.(c) Business Strategy,Strategi padatingkat ini menjabarkan bagaimanamerebut pasaran ditengahmasyarakat, bagaimanamenempatkan organisasi di hati parapenguasa, para pengusaha, paraanggota legislatif, para politisi dan lain sebagainya. (d) Functional Strategy, Strategi ini merupakanstartegi pendukung dan untukmenunjang suksesnya strategi lain.Ada dua alasan, mengapakegiatan komunikasi memerlukanstartegi. Pertama, karena pesan yangkita sampaikan harus diterima dalamarti receive tetapi ada juga accepted.Kedua, agar kita bisa mendapatkanrespon yang diharapkan. Dalam halini, strategi tidak bisa dipisahkan dariproses komunikasi yang melibatkankomponen-komponen sepertikomunikator, pesan, saluran,komunikan dan efek. Strategi adalahlangkah-langkah atau jalan-jalan penunjuk yang meyakinkan yang harus ditempuh dalam mencapaitujuan, strategi sifatnya jangkapanjang, sedangkan taktik sifatnyajangka pendek. Strategi dan taktikadalah cara untuk melaksanakanperencanaan.

\section{Tahapan-Tahapan Strategis}

1. Perumusan Strategi

Dalam perumusan strategi, konseptorharus mempertimbangkan mengenaipeluang dan ancaman eksternal,menetapkan kekuatan dan kelemahansecara internal, menetapkan suatu objektifitas, menghasilkan strategialternatif dan memilih strategiberusaha menemukan masalah. masalah yang terjadi dari peristiwayang ditafsirkan berdasarkan kontekskekuatan,

kemudian mengadakananalisis mengenai kemungkinankemungkinan serta memperhitungkan pilihan-pilihan dan langkah-langkah yang dapat diambil dalam rangka gerak menuju kepada tujuan itu.

2. Implementasi Strategi

Setelah merumuskan dan memilihstrategi yang diterapkan, makalangkah berikutnya adalah melaksanakan strategi yangditerapkan tersebut. dalam tahapanpelaksanaan strategi yang telahdipilih sangat membutuhkankomitmen dan kerja sama dari seluruhunit, tingkat dan anggota organisasi.

3. Evaluasi Strategi

Tahap akhir dari menyususn strategiadalah evaluasi implementasi strategi.Evaluasi startegi diperlukan karenakeberhasilan yang telah dicapai dapatdiukur kembali untuk menetapkan tujuan berikutnya. Evalusasi menjaditolak ukur untuk strategi yang akandilaksanakan kembali oleh suatuorganisasi dan evaluasi sangatdiperlukan untuk menentukan sasaranyang dinyatakan telah tercapai Adatiga kegiatan mendasar untukmengevaluasi strategi, yakni : (a)Meninjau faktor-faktor eksternal daninternal yang menjadi dasar strategi.Adanya perubahan yang akanmenjadi suatu hambatan dalammencapai tujuan. Begitu pula denganfaktor internal yang diantaranyastrategi tidak efektif atau hasilmplementasi yang buruk dapatberakibat buruk bagi hasil yang akandicapai. (b) Mengukur prestasi(membandingkan hasil yangdiharapkan dengan kenyataan).Proses ini dapat dilakukan denganmenyelidiki penyimpanan darirencana, mengevaluasi prestasiindividual, dan menyimak kemajuanyang dibuat kearah pencapaiansasaran yang dinyatakan. Kriteriauntuk mengevaluasi strategi harusmudah diukur dan mudah dibuktikan.Kriteria yang meramalkan hasil lebihpenting dari pada kriteria yangmengungkapkan apa yang terjadi. (c)Mengambil tindakan korektif untukmemastikan bahwa prestasi sesuaidengan rencana. Dalam hal ini tidakharus berarti yang ada ditinggalkanatau merumuskan strategi 
baru.Tindakan korektif diperlukan bilatindakan atau hasil tidak sesuaidengan hasil yang dibayangkansemula atau pencapaian yangdiharapkan.

Arti penting dari penelitian ini dapatdiklasifikasikan ke dalam dua kategori:praktis dan teoritis. Peneliti percayabahwa penelitian ini akan memberikankontribusi yang baik teoritis dan praktisuntuk mengajar dan belajar bahasa Inggris.Secara teoritis: memberikan informasikepada peserta didik dan guru bahasaInggris tentang pengaruh lingkunganterhadap kemampuan dan kelancaranberbicara bahasa Inggris secaira Lisan Praktis: memberikan masukan baik untuk siswa/siswi atauguru bahasa inggris untuk meningkatkan kompetensi komunikatif mereka.

\section{METODOLOGI PENELITIAN \\ Metode Penelitian}

Penelitian ini merupakan penelitiandeskriptif kualitatif yang dilaksanakandi Sekolah Menengah Pertama Islam Terpadu (SMPIT) Nurul Ishlah Banda Aceh yang berlokasi di Pango, Ulee Kareng. subjek penelitian yaitu siswa/siswi yang tengah belajar bahasa Inggris di kelas. Sumberdari data penelitian ini didapatkan dariwawancara dengan guru, mengikutikegiatan pembelajaran, dan merekamsemua kegiatan sebagai bukti dan penguatuntuk pengambilan data melaluiwawancara dan sit in di kelas.

\section{Teknik Pengambilan Sampel}

Subjek pada penelitian ini adalahsiswa yang menjalani proses belajar mengajar pelajaran bahasaInggris di kelas. Karenasubjek dalam penelitian ini homogen makadengan menggunakan teknik quotasampling peneliti mengamati 25 oranguntuk kepastian peneliti.

Data akan dikumpulkan daripelaksanaan strategi komunikasi selama proses belajar mengajar bahasa inggris di kelas. Data akan diambil dari tiga sumber antara lain :

1. Kegiatan : kegiatan proses belajar mengajar selama di kelas. Data akan dibatasi hanya pada diskusi . Melalui diskusi dengan topik langsung diberikan, udahmudahan ucapan-ucapan yang dihasilkan dapat menggambarkan strategi komunikasi yang digunakan.

2. Informan: guru dan siswa/siswi yang terlibat dalam proses belajar mengajar pelajaran bahasa inggris di kelas. Guru adalah mentor yang membimbing kegiatan berjalan selama proses belajar mengajar yangdilakukan.

3. Dokumentasi : melakukan pemotretan selama proses belajar mengajar pelajaran bahasa inggris. Pemotretan akan memberikaninformasi pendukung tentang strategikomunikasi yang digunakan olehpelajar bahasa Inggris.

\section{HASIL DAN PEMBAHASAN}

\section{Hasil dan Pembahasan}

Ada beberapa strategi komunikasiyang digunkan oleh siswa di Sekolah Menengah Pertama Islam Terpadu (SMPIT) Nurul Ishlah Banda Aceh dan alasan penggunaanstrategi komunikasi. strategi komunikasitersebut adalah:

\section{Intruksi Kelas (Classroom Intruction)}

Peneliti melakukan interview dan oberservasi kelas di SMPIT Nurul Ishlah Banda Aceh. Peneliti melakukan wawancara dengan guru dan kepala sekolah untuk informasi tambahan tentang sekolah. Wawancara dilaksanakan selama 4 kali. Tentang observasi kelas, peneliti 
mengamati guru ketika mengajar. Hal ini dimulai dari pembukaan proses belajar mengajar dan penutup.

\section{Pembukaan (opening)}

Berdasarkan hasil observasi peneliti bahwa guru tidak mengajar secara tiba-tiba artinya bahwa guru tersebut sudah melakukan persiapan sebelumnya. Namun demikian, guru membiarkan siswa/siswi melakukan rutinitas mereka, berdoa bersama. Setelah itu, guru memulai kelas dengan salam kepada siswa/siswi. Guru bertanya "how are you today?" or "are you well today?" and "did you study last night?" Guru tersebut disalami oleh siswa/siswi oleh pertanyaan sebelum memulai pelajaran. Siswa/siswi akan merespon salam secara langsung. Guru tersebut akan membuka atmosfer pembelajaran pada sesi pembukaan supaya menghindari situasi yang tidak dinginkan. Selanjutnya, siswa/siswi diharapkan untuk menikmati kelas. Guru kemudian memeriksa kehadiran siswa/siswi dengan memanggil mereka. Pada pertemuan berikutnya, guru hanya memeriksa siswa/siswi yang tidak hadir pada kelas hari itu. Peneliti mengutip wawancara dengan guru tentang cara pembukaan di keas sebagai berikut :

"I think it is same like another teacher, we have do'a, I attend all of my students five minute. Sometimes I just call all the students, sometimes I ask the students who does not come, who is sick today, oh Raihana does not come. It is not the same way".

Guru kemudian melakukan brainstormingide-ide yang berhubungan dengan topik pada hari itu supaya membuka pelajaran. Guru menyuruh siswa/siswi apa topiknya dan siswa/siswi memberikan jawaban dengan bermacam-macam ide. Guru mendorong mereka untuk berpikir secara kritis dan menjelaskan tujuan-tujuan atau target-target materi yang diajarkan. Oleh karena itu. Siswa/siswi mengetahui apa yang mereka harus capai setelah pembelajaran ini.

Pembukaan pelajaran merupakan bagian vital dalam proses pembelajaran, akan tetapi sering tidak sesuai dalam pengajaran. Banyak guru sangat tekun untuk mendapatkan siswa secara aktif dilibatkan dalam pembelajaran, akan tetapi masih banyak yang gagal dalam memperkenalkan pelajaran kepada siswanya karena mereka kurang keterampilan dalam membuka pelajaran. Menurut Stewart (2011) ; Hansen dan Moore (2012) bahwa pembukaan pelajaran adalah aspek krusial dalam menentukan kesuksesan siswa. Artinya bahwa pembukaan dalam pembelajaran merupakan suatu hal yang paling penting untuk keberhasilan pembelajaran. Lingkungan pembelajaran yang kurang baik akan meningkat apabila guru tidak mampu membuka pelajaran dengan baik. Oleh karena itu, guru seharusnya mampu membuka pelajaran dengan cara yang lebih menarik.

\section{Pelaksanaan}

Peneliti mengamati bahwa guru ketiak mengajar pada siswa kelas VIII dan IX. Walaupun materi yang diajarkan berbeda, cara pengajaran guru pada ketiga kelas sama. Observasi pertama pda kelas siswa VIII. Topik yang diajarkan adalah Past Tenses menggunakan lagu yang berjudul "Yesterday". Jika guru mengintegrasi tiga kemampuan yakni listening, wiriting dan reading. Guru menyuruh satu orang siswa menulis lirik lagu pada papan tulis. Sementara siswa-siswa lainnya sedang menulis lirik, guru mempersiapkan media (Laptop, LCD, and loudspeaker). Guru menyatakan Laptop, LCD dan In focus saya gunakan. Setelah siswa/siswi menulis lirik, mereka mendengar lagu dengan mengisi jawaban yang tersedia didalam kotak. Jawaban akan diberikan didalam kotak agar membuat siswa lebih mudah mengisi lirik yang hilang. Lagu tersebut diulang sampai empat kali karena satu kali belum cukup. Guru memberikan petunjuk kepada siswa "OK... listen carefully". I will repeat four times and then you fill in the blank". Kemudian jawaban tersebut didiskusikan bersama dengan menuliskan jawaban di papan tulis. Siswa tidak memeriksa jawaban mereka masing-masing 
akan tetapi mereka menganti lembar jawaban dengan teman mereka agar dikoreksi oleh rekannya da mereka mendiskusikannya bersama. Teacher said," after you finished, please change to your friends. Don't check your work by yourself ".Dari lagu, guru juga menjelaskan tentang materi Past tense dan nominal sentences. Selain itu, guru tersebut mengajarkan kepada mereka melalui video bagaimana pengucapan kata kerja bentuk lampau (kata kerja regular dan irregular).Ini tulisan yang guru ajarkan : Pengucapan "ed" terdapat tiga kelompok adalah sebagai berikut :

Kelompok 1 : ketika "ed" diucapkan sebagai /t/ "e" tidak ucapkan dan "d" diucapkan sebagai /t/. "ed" berbunyi seperti /t/

E.g: $s$ sh $\quad$ ch $k \quad k \quad p \quad f$

Missed mist

Washed washt

Watched watcht

Worked workt

Stopped stopt

Laugh laught

Kelompok 2: ketika 'ed' diucapakan sebagai /d/

' $e$ ' is not pronounced, and ' $d$ ' is pronounced as /d/

e.g: offer offered

lofferd/

answer-answered

lanswerd/

sue-sued

/sued/

study-studied

/sutyd/

lie-lied

lied/

show-showed

/showd/

Kelompok 3: ketika 'ed' is diucapkan penuh sebagai /id/ td ketika infinitif diakhiri dengan konsonan

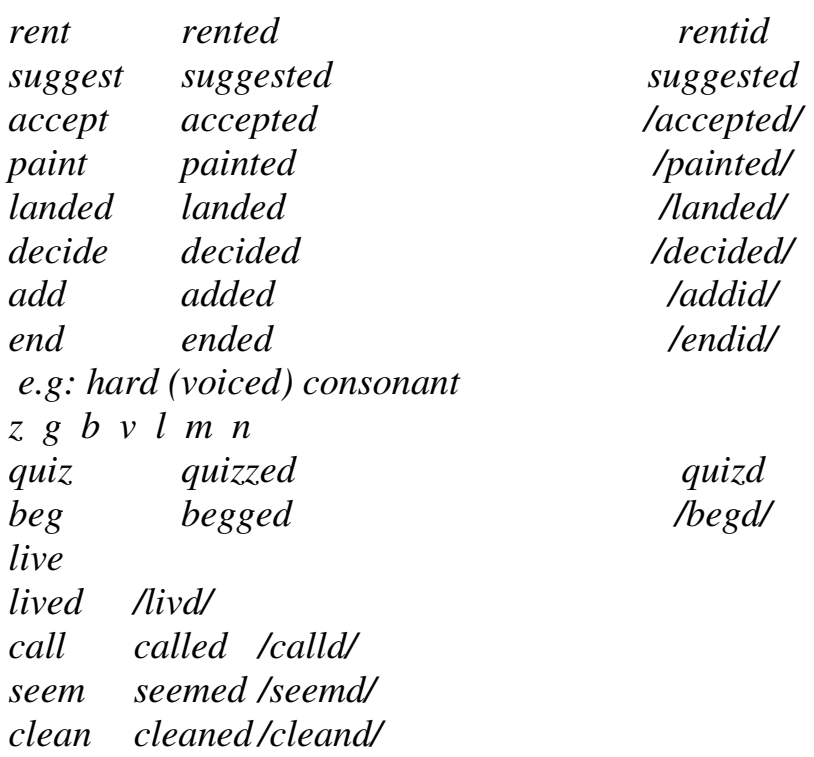

Kesalahan Umum 
1. Pengucapan 'ed' as /id/ after all verbs

Helped not helped this is /helpt/

Walked not walked it is /walkt/

Coughed not coughed but /cought/

Ordered not ordered but /orderd/

Married not marryid but /marryd/

Arrived don't say arrived, say /arrivd/

Changed don't say changed, say/changd/

Listened don't say listened, say /listend/

2. Tidak diucapkan /id/ secara jelas pada akhir kata kerja yang diakhiri ' $t$ ' or ' $d$ ' Invited not /invitd/ but invitid

Demand not /demand/ but demanded

Guru berkata " Ulangi setelah saya ya OK... (Siswa meniru pengucapan dari guru tersebut) akhirnya, guru tersebut menyuruh siswa untuk menyanyikan lagu didepan kelas. Guru menyatakan "OK... beberapa siswa maju ke depan kelas untuk menyanyikan lagu bersama, one...two...three... ini lirik lagu dalam bahasa inggris.

Yesterday, all my troubles (1)... in far away

Now, it (2) ... as though they're here to stay

Oh, I believe in yesterday

Suddenly, I'm not half the man (3) ...to be

There's a shadow hanging over me

Oh, Yesterday (4) ... suddenly

Why she (5)...to go I don't know

She wouldn't say

I (6) ... something wrong now. I (7) ...for Yesterday

Yesterday, love (8) ... such an easy game to play

Now I (9) ... a place to hide away

$\mathrm{Oh}, \mathrm{I}(10)$... in Yesterday

$M m \ldots . . . M m \ldots M m$

Observasi kedua yang di kelas IX. Topik yang dibahas tetang pengumuman dan peringatan. Guru menjelaskan materi-materi dengan menunjukkan banyak contoh-contoh notice, caution, dan warning dalam slide powerpoint. Penjelasan guru :

Notice (salah satu teks fungsional yang berupa petunjuk agar seseorang melakukan/ tidak melakukan sesuatu).

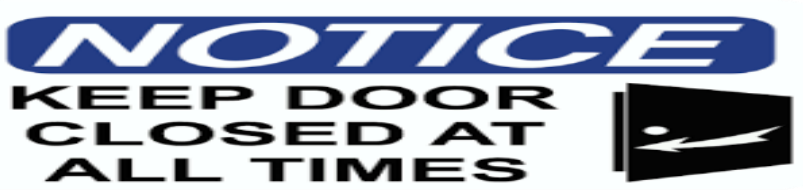

Contoh: keep door closed at all times

Caution (peringatan atau saran yang ditunjukkan untuk public tentang sebuah bahaya atau resiko yang mungkin terjadi)

Contoh: chemical Storage only. No food or drink in this unit 


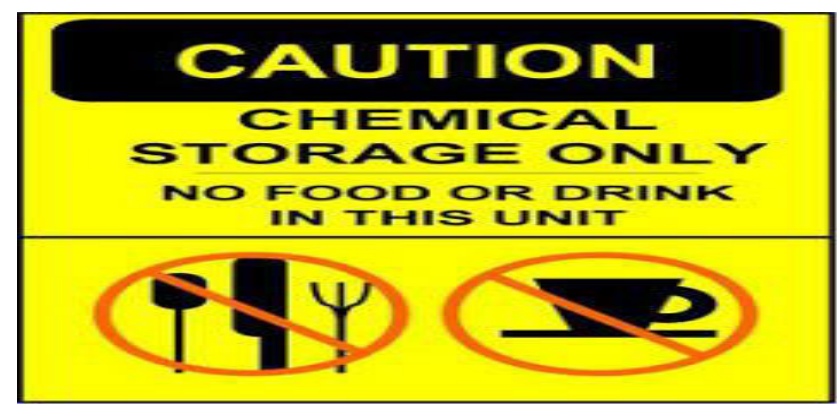

Warning (larangan agar supaya seseorang tidak melakukan hal tersebut karena dianggap sangat berbahaya): Gloves and masks. Should be worn when working in this area

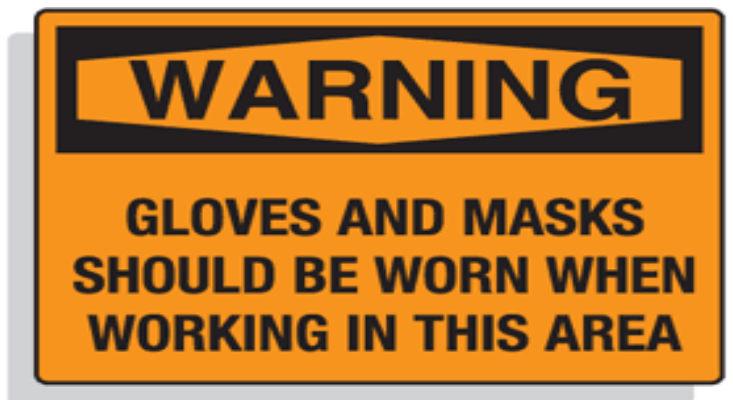

Dari penjelasan di atas, guru menyuruh siswa untuk menciptakan pertanyaan. Dibawah ini contoh pertanyaan :

1. Dimana biasa kami temukan seperti pemberitahuan tersebut?

2. Kami biasanya menemukan pemberitahuan di ...

3. Teks tentang apa?

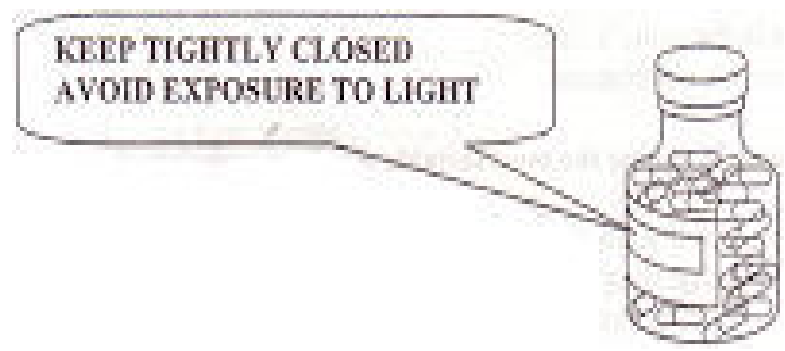

\section{Penutupan (Closing)}

Diakhir pengajaran, guru memberikan kesempatan kepada siswa untuk bertanya pelajaran yang tidak dipahami. Guru juga mereview beberapa penjelasan pelajaran yang diajarkan. Guru menyimpulkan bahwa materi-materi dari pemahaman siswa melalui pertanyaan. Akhirnya, guru memberikan tugas rumah kepada mereka. Sebelum penutupan di kelas, guru memberikan motivasi, spirit, dan apresiasi kepada siswa mereka. Guru tidak lupa berkata dengan ungkapan seperti nice to meet you today, see you on the next meeting, good bye and thank you for your attention. The teacher stated:I think enough for today. Don't forget to study ya. See you next week.

\section{Evaluasi (Evaluation)}

Guru mengevaluasi siswa dalam dua tipe tes : formatif dan summatif. Menurut Brown (2007), ujian formatif disebut penilaian informalyang menilai siswa dalam proses pembelajaran 
untuk menciptakan kemampuan dan keterampilan mereka. Guru menyatakan dalam interview. Dalam UTS (formatif) skor siswa itu murni tanpa penambahan ulangan harian. Dalam penilaian formatif, guru mengevaluasi proses pembelajaran siswa. Hasil penilaian berdasarkan kemampuan siswa tanpa pemberian skor tambahan. Oleh karena itu, siswa harus belajar keras untuk mencapai skor terbaik dari ujian mereka. Guru juga menerapkan ujian summatif atau penilaian formal yang dilaksanakan pada akhir semester. Sistem ujian summatif merupakan kolaborasi dari beberapa ujian: harian, bulanan dan hasil tugas-tugas. Guru melaksanakan ujian ini untuk mengukur kemampuan siswa. Brown (2007) menjelaskan bahwa ujian summatif muncul pada akhir pelajaran, unit atau kursus. Hal ini untuk mengukur atau merangkum apa yang siswa peroleh. Guru menyatakan dalam interview dalam Ujian Tengah Semester (midtest), skor siswa murni. Artinya bahwa skor mereka tidak ditambahkan dari tugas harian, mingguan dan bulan. Namun demikian, ujian akhir semester, skor dikolaborasi dari seluruh ujian (harian, mingguan, dan bulanan).

Berdasarkan hasil interview di atas, bahwa guru mengevaluasi siswa dengan menggunakan ujian formatif dan ujian summatif. Formatif berasal dari aktivitas sehari-hari seperti tugas, penampilan dalam kelas, diskusi kelompok dan pekerjaan rumah. Evaluasi lainnya adalah ujian summatif; skor didapatkan dari skor harian, mingguan dan bulanan. Ujian secara umum dilaksanakan setiap bulan setelah mereka menyelesaikan satu atau dua topik.

\section{Word coinage}

Word coinage adalah cara pembelajar bahasa Inggris untuk mengatakan sesuatu dalam bahasa Inggris, tetapi mereka tidak tahu bagaimana mengatakannya, sehingga mereka memberikan deskripsi sederhana tentang apa yang mereka maksud. Dari temuan penelitian tentang penggunaan kata koin dalam proses belajar mengajar bahasa inggris oleh siswa/siswi, itu menunjukkan bahwa mata uang kata adalah salah satu solusi yang dapat diterapkan oleh pelajar bahasa Inggris untuk pengiriman cara mereka ke orang lain karena keterbatasan mereka dalam kosakata. Ini adalah salah satu strategi komunikasi jenis yang dapat diterapkan oleh pelajar bahasa Inggris, yang mana bahasa Inggris sebagai bahasa kedua.

\section{Code switching}

Alih kode (Code switching) adalah campuran bahasa target dan bahasa sumber dalam frase. Alih kode adalah salah satu teori strategi komunikasi, dan hasil penelitian ini menunjukkan bahwa alih kode adalah salah satu strategi komunikasi yang diterapkan oleh pelajar bahasa Inggris dalam proses belajar mengajar pelajaran bahasa inggris, bahwa itu berarti temuan penelitian yang didukung teori grand strategi komunikasi dinyatakan oleh Brown (2007). Penerapan kode switching adalah otonom oleh pelajar bahas Inggris ketika sulit untuk menemukan kata bahasa Inggris yang mereka maksud dibandingkan dengan bantuan yang sama yaitu dengan meminta bantuan, strategi ini mudah diterapkan oleh pelajar bahasa Inggris dan umumnya diterapkan oleh pelajar yang sudah lancar dalam menggunakan Bahasa Inggris. Konsep dasar strategi komunikasi tentang strategi kompensasi menyatakan tentang banding untuk membantu, itu berarti temuan penelitian ini mendukung teori grand strategi komunikasi. 


\section{KESIMPULAN}

Kesimpulan dari penelitian yangdiambil dari temuan penelitian dan hasil diskusi adalah sebagai berikut:

1. Strategi komunikasi harus diperkenalkan kepada pelajarbahasa Inggris karena sangatmembantu bagi pelajar bahasaInggris untuk memperjelas carabelajar bahasa Inggris secaraoptimal.

2. Lingkungan sangat mendukungpelajar bahasa Inggris untukberlatih kemampuan berbicara,maka sangat di anjurkan bagisiswa untuk lebih seringberlatihmenggunakan Bahasa targetdalam kegiatan sehari-hari.

3. Class intruction (instruksi kelas) sangat mempengaruhi bagaimana guru menciptakan komunikasi yang baik di dalam kelas yaitu mulai dari pembukaan, proses belajar mengajar dan penutup.

\section{REFERENSI}

Bialysok, E. 1990. Communication Strategies: A Psychological Analysis of Second-language Use. London: Brasil Blackwell Ltd.

Brown, D. 2007. Priciples of Language Learning and Teaching. New York: Pearson Education, Inc

Brown, H.D. 2007. Teaching by Principles : An interactive approach to language pedadogy. New York. : Pearson Education.

Donyei, Z. 2007. Research Methods in Applied Linguistics.Oxford: Oxford University Press.

Ellies, R.1985. Understanding Second Languge Aquisition. London: Oxford University Press.

Faerch, C and Kasper, G.1983. Strategies in Interlanguge Communication.New York: Longman

Gan, Z. 2013. Understanding L2 Speaking Problems: Implications for ESL Curriculum Development in a Teacher Training Institution in Hong Kong,Australian Journal of Teacher Education: Vol. 37: Iss. 1, Article 3. Retrieved from http://ro.ecu.edu.au/ajte/vol37/iss1/3

Hansen, J dan Moore, K.D. 2012. Effective Strategies for teaching in k-8 classroom. United Kingdom : Sage Publication, Ltd.

Mulyana, D. 2007. Ilmu Komunikasi Suatu Pengantar, Bandung: PT. Remaja Rosdakarya.

Rakhmat, D. 2007. Psikologi Komunikasi, Bandung: PT. RemajaRosdakarya.

Stewart, C. 2011. Interviewing : Principal and Practices. New York : McGraw Hill.

Supratiknya, A. 1995. Komunikasi Antarpribadi Tinjauan Psikologis, Yogyakarta: Kanisius.

Thornbury, S. 2008. How to Teach Speaking. London: Longman. 